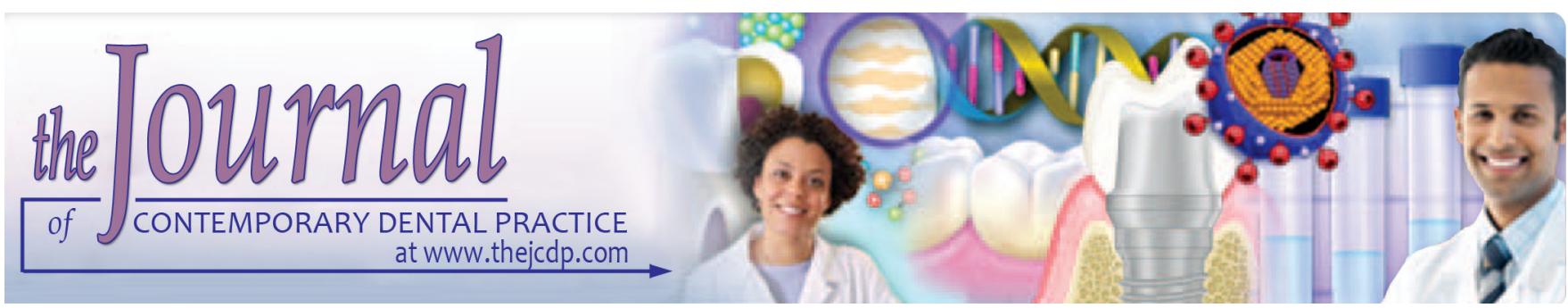

\title{
Successful Management of Lip and Oral Venous Varices by Photocoagulation with Nd:YAG Laser
}

\author{
1Dante Migliari, ${ }^{2}$ Rodrigo R Vieira, ${ }^{3}$ Edgar K Nakajima, ${ }^{4}$ Luciane H Azevedo
}

\begin{abstract}
Aim: This study assessed the effectiveness of photocoagulation with Nd:YAG laser in the treatment of lip and oral venous varices.

Materials and methods: Sixteen consecutive patients (eight men and eight women, mean age 56 years) diagnosed as having either lip or oral venous varices, were examined and treated with a noncontact $\mathrm{Nd}$ :YAG laser. As lesions were small (less than $1 \mathrm{~cm}$ ), round or oval in shape, flat, dark to blue in color and symptomless, patients sought for treatment either for esthetic reason, bleeding or cancerophobia-related concern.
\end{abstract}

Results: All but one lesion were successfully treated with only one irradiation exposure. Healing was completed in about 2 to 4 weeks; none of the patients experienced complications or recurrence. Pain was out of any major concern during immediate follow-up.

Conclusion: Although photocoagulation with Nd:YAG laser did not outperform the effectiveness observed with diode laser (data shown in a previous study), ${ }^{17}$ it proved to be safe and effective for the treatment of lip and oral varices, with consistent results.

Clinical significance: Most of patients with oral and lip varices only need some clinical advice regarding the their nature of their lesions. Yet, for those who seek treatment for this conditions, the use Nd:YAG laser is an option as it yields satisfactory outcomes.

Keywords: Lip and oral vascular diseases, Nd:YAG laser, Photocoagulation, Venous varices.

How to cite this article: Migliari D, Vieira RR, Nakajima EK, Azevedo LH. Successful Management of Lip and Oral Venous

\footnotetext{
${ }^{1}$ Department of Stomatology, School of Dentistry, University of São Paulo, São Paulo, Brazil

${ }^{2,3}$ Department of Laser in Dentistry, University of São Paulo São Paulo, Brazil

${ }^{4}$ Department of Health Care (COSEAS), University of São Paulo, São Paulo, Brazil

Corresponding Author: Dante Migliari, Clinician and Associated Professor, Department of Stomatology, School of Dentistry University of São Paulo, São Paulo, Brazil, Phone: 551138641372 e-mail: dantemigliari@gmail.com
}

Varices by Photocoagulation with Nd:YAG Laser. J Contemp Dent Pract 2015;16(9):723-726.

Source of support: Nil

Conflict of interest: None

\section{INTRODUCTION}

Venous varix is a type of acquired vascular malformation that represents focal dilation of a single vein, mostly seen in elderly individuals and on the legs. ${ }^{1}$ Oral sites most affected by venous varix are the ventral surface of the tongue, and buccal and retrocommissural mucosae. When it occurs on the lip it is also known as venous lake. ${ }^{2}$ Clinically, lip and oral venous varix (L-OVV) lesions usually appear as dark-blue to violaceous papules, which blanch when pressure is applied.

Histologically, they are lined by a single layer of flattened endothelial cells and a thick wall of fibrous tissue. ${ }^{3}$ Once formed, an L-OVV lesion persists throughout life. Except for occasional hemorrhaging and possible cosmetic problems, the course of the lesion is uncomplicated.

Several modalities of treatment for vascular lesions have been described in the literature including cryosurgery with liquid nitrogen, ${ }^{4}$ surgical excision, ${ }^{4}$ laser photocoagulation, ${ }^{2,5}$ laser vaporization, ${ }^{6}$ infrared coagulation, ${ }^{7}$ and sclerosing agents. ${ }^{9}$ In the mouth, mainly on the lip, there is an esthetic challenge when surgery and/ or sclerosing agents are used, particularly if lesions are larger than the usual size. ${ }^{7,8}$ Treatment with high-energy lasers is an option, since scarring is minimal or not detectable at all. ${ }^{9}$

The Nd:YAG laser beam has a wavelength of $1064 \mathrm{~nm}$; it is poorly absorbed in water and selectively absorbed by hemoglobin. The laser beam penetrates deeply into the tissue, gradually emits heat, and thus causes coagulation down to the depth of about 7 to $10 \mathrm{~mm}$, in a process called photocoagulation. ${ }^{10}$ 
This study was undertaken to assess the effectiveness of Nd:YAG laser in the treatment of this condition. A brief comparison with the high-intensity diode laser, a device used in a previous study conducted in similar fashion, is also included.

\section{MATERIALS AND METHODS}

\section{Patients}

A total of 16 patients (eight men and eight women), age ranging from 39 to 76 years (mean 56 years) were included in this study. There were 16 lesions, of which three were on the lips, four on the labial mucosa, and three on the buccal mucosa. The mean surface diameter was $0.7 \mathrm{~cm}$ (SD 0.3). Diagnosis was made on a clinical basis, making sure that lesions were easily compressed and slowly blanching on applying pressure.

\section{Laser Procedure}

A Nd:YAG laser (wavelength of $1064 \mathrm{~nm}$ ), with power of 2-W (Power Laser ${ }^{\mathrm{TM}}$ ST6, Lares Research ${ }^{\circledR}$, San Clemente, CA) was used in on contact mode, under local anesthesia.

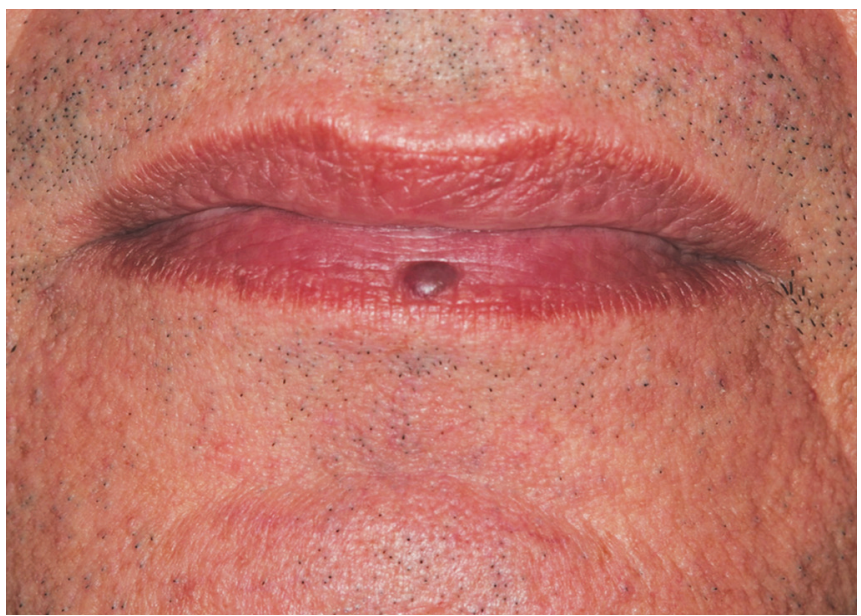

Fig. 1: A patient with a venous lake on the vermillion border of the lower lip before photocoagulation with Nd:YAG laser

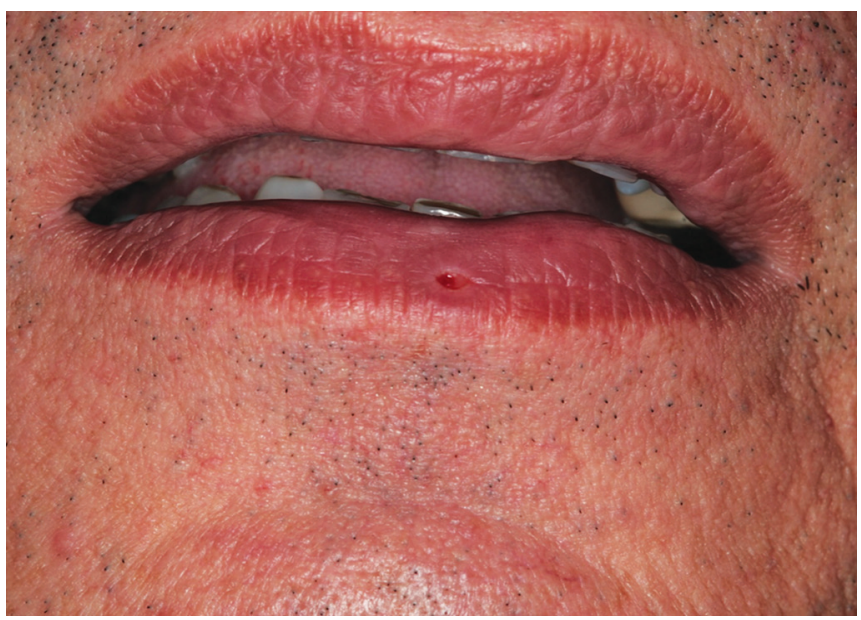

Fig. 3: Photograph after 7 days of follow-up
Irradiation was delivered using a flexible quartz fiber $320 \mu \mathrm{m}$ in diameter, kept 2 to $3 \mathrm{~mm}$ away from the lesion, at pulse frequencies of $50 \mathrm{~Hz}$ for 10 seconds, proceeding with quick circular movements. The endpoint of treatment was blanching and visible shrinkage of the lesion. When necessary, another cycle was performed after a 30 seconds interval to prevent heat damage. All lesions were photographically documented at all stages of treatment and during the healing process.

\section{RESULTS}

All but one patient received only one irradiation exposure. Immediately after laser treatment, all patients developed slight swelling of the treated area that lasted 1 to 2 days. None of the patients experienced bleeding or postoperative pain. The tissue sloughing occurred within 2 to 3 days, and healing with re-epithelization was complete 2 to 4 weeks after treatment with minimal or no scarring. None of the typical adverse effects (significant scars, hyper- or hypopigmentation, atrophy, or wrinkled texture) were observed after complete healing (Figs 1 to 4 ).

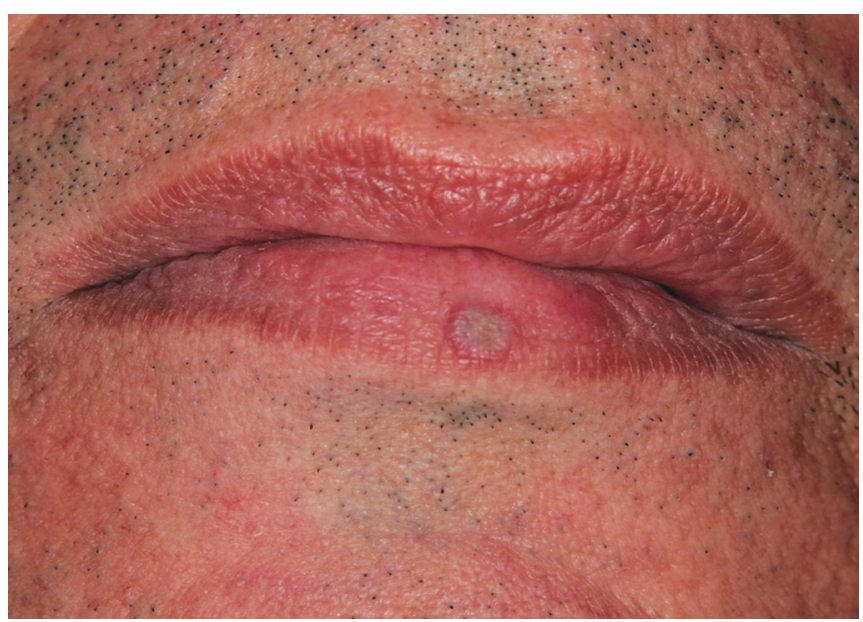

Fig. 2: Immediately after the photocoagulation

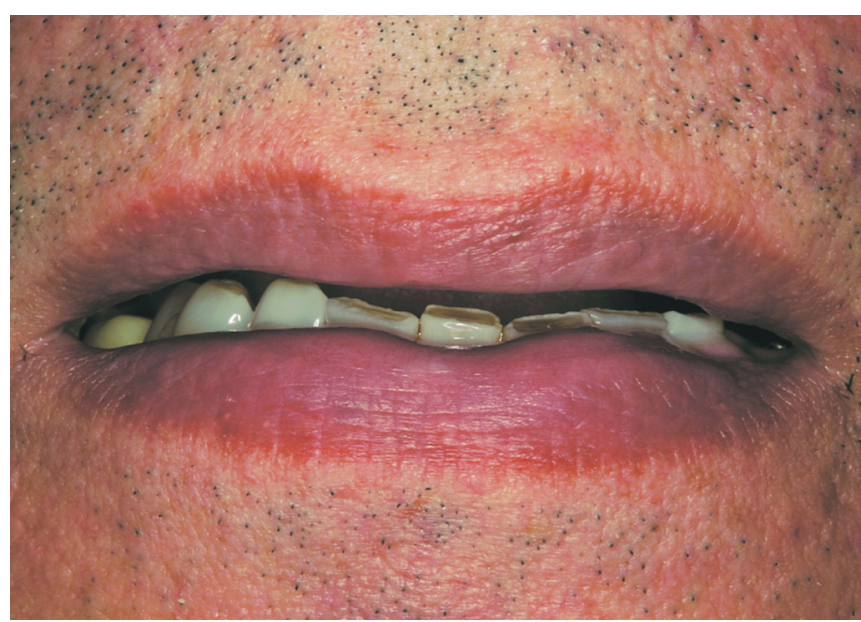

Fig. 4: Photograph after 3 months of follow-up. No visible scar can be seen 


\section{DISCUSSION}

The Nd:YAG laser system has been marketed as a device that can be interchangeably used on hard and soft oral tissues. On soft tissues, it has been used in periodontal procedures, such as debridement of diseased epithelial lining, crown lengthening, vestibuloplasty and reduction of drug-induced gingival hyperplasia, and for removing benign oral lesions and leukoplakia. ${ }^{11-13}$ On hard tissues, especially related to the mineralized surface of teeth, it has been used for the treatment of dental hypersensitivity and the final step of caries removal. ${ }^{14,15}$ In addition to this, Nd:YAG laser can also be used to photocoagulate vascular lesions since its light beam can be selectively absorbed by hemoglobin. ${ }^{10}$

Another aspect is related to the energy delivery on tissue. The long-lasting pulse of Nd:YAG laser is capable of delivering energy at a frequency between 50 and 60 minutes, and is able to dissipate the retained heat, thus preventing damage to the healthy structures adjacent to lesions. Other lasers, such as the argon and diode type, are able to deliver more powerful and lasting pulses, which are more likely to produce tissue damage due to their reduced capability of dissipating the eventual overheating.

In the present study, the Nd:YAG laser photocoagulation technique was effective in the treatment of L-OVV. Cryosurgery and electrocautery are also low-cost surgical devices, but may cause scarring, particularly in lesions on the borders of the lips.

Our previous studies have shown the effectiveness of diode laser in the surgical removal of L-OVV lesions. ${ }^{16,17}$ By comparison, both diode and Nd:YAG lasers have produced very similar results in terms of ease-of-handling, bleeding control, uneventful postoperative period and esthetic healing. The choice of either of these two lasers for performing treatment of oral venous lesions will meet the important criteria for resolution of the lesion without producing discernible scar. In spite of being more expensive, Nd:YAG laser has multiple uses and may meet the demands of a surgical approach to oral care.

As is the case with all surgical techniques, in which it is not possible to recover a sample of the surgically treated lesion for histopathological examination, an accurate clinical diagnosis of an L-OVV lesion should be made. In any case in which a precise diagnosis cannot be reached, a biopsy should be performed before the use of laser therapy.

\section{CONCLUSION}

The present study showed that the $\mathrm{Nd}$ :YAG laser photocoagulation technique provided a safe and effective treatment, with a consistent results.

\section{CLINICAL SIGNIFICANCE}

Most of patients with oral and lip varices only need some clinical advice regarding the nature of their lesions. Yet, for those who seek treatment for this conditions, the use $\mathrm{Nd}$ :YAG laser is of an option as it produces consistent and satisfactory outcomes.

\section{ACKNOWLEDGMENTS}

We are grateful to the Special Laboratory of Lasers in Dentistry, School of Dentistry, University of São Paulo, and to the State of São Paulo Research Foundation for their continuous support in this research (FAPESP 07/55487-0).

\section{REFERENCES}

1. Regezi JA, Sciubba JJ, Jordan RCK. Oral Pathology. Clinical Pathologic Correlations. 5th ed. St Louis: Saunders, Elsevier; 2008. 110-111 p.

2. Alvarez-Camino JC, España-Tost AJ, Gay-Escoda C. Endoluminal sclerosis with diode laser in the treatment of orofacial venous malformations. Med Oral Patol Oral Cir Bucal 2013 May 1;18(3):486-490.

3. Alcalay J, Sandbank M. The ultrastructure of cutaneous venous lakes. Int J Dermatol 1987 Dec;26(10):645-646.

4. Suhonen R, Kuflik EG. Venous lakes treated by liquid nitrogen cryosurgery. Br J Dermatol 1997 Dec;137(6):1018-1019.

5. Neumann RA, Knobler RM. Venous lakes (Bean-Walsh) of the lips-treatment experience with the argon laser and 18 months follow-up. Clin Exp Dermatol 1990 Mar;15(2):115-118.

6. del Pozo J, Peña C, Garcia Silva J, Goday JJ, Fonseca E. Venous lakes: a report of 32 cases treated by carbon dioxide laser vaporization. Dermatol Surg 2003 Mar;29(3):308-310.

7. Ah-Weng A, Natarajan S, Velangi S, Langtry JA. Venous lakes of the vermillion lip treated by infrared coagulation. Br J Oral Maxillofac Surg 2004 Jun;42(3):251-253.

8. Kuo HW, Yang CH. Venous lake of the lip treated with a sclerosing agent: report of two cases. Dermatol Surg 2003 Apr;29(4):425-428.

9. Chapas AM, Geronemus RG. Our approach to pediatric dermatologic laser surgery. Lasers Surg Med 2005 Oct;37(4): 255-263.

10. Vesnaver A, Dovsak DA. Treatment of large vascular lesions in the orofacial region with the Nd:YAG laser. J Craniomaxillofac Surg 2009 Jun;37(4):191-195.

11. White J, Goodis H, Rose C. Use of the pulsed Nd:YAG laser for intraoral soft tissue surgery. Lasers Surg Med 1991;11(5): 455-461.

12. Zhang YM, Chen K. Application of Nd:YAG laser for gingivoplasty during orthodontic treatment. Di Yi Jun Yi Da Xue Xue Bao 2002 Sep;22(9):841-842.

13. Montebugnoli L, Frini F, Gissi DB, Gabusi A, Cervellati F, Foschini MP, Marchetti C. Histological and immunohistochemical evaluation of new epithelium after removal of oral leukoplakia with Nd:YAG laser treatment. Lasers Med Sci 2012 Jan;27(1):205-210. 
14. Blatz MB. Laser therapy may be better than topical desensitizing agents for treating dentin hypersensitivity. J Evid Based Dent Pract 2012 Sep;12(3 Suppl):229-230.

15. White JM, Goodis HE, Setcos JC, Eakle S, Hulscher BE, Rose CL. Effects of pulsed Nd:YAG laser energy on human teeth: a three-year follow-up study. J Am Dent Assoc 1993 Jul;124(7):45-51.
16. Azevedo LH, Galletta VC, Eduardo CP, Migliari DA. Venous lake of the lips treated using photocoagulation. Photomed Laser Surg 2010 Apr;28(2):263-265.

17. Azevedo LH, Del Vechio A, Nakajima E, Galletta V, Migliari DA. Lip and oral venous varices treated by photocoagulation with high-intensity diode laser. Quintessence Int 2013 Feb;44(2):171-174. 